\title{
A PESQUISA COMO UM MEIO PARA A PERMANÊNCIA NO ENSINO SUPERIOR PÚBLICO: O CASO DO PROGRAMA BOLSA DE DESENVOLVIMENTO ACADÊMICO NA UNIVERSIDADE FEDERAL FLUMINENSE
}

\author{
RESEARCH AS A MEANS FOR PERMANENCE IN PUBLIC HIGHER EDUCATION: \\ THE CASE OF THE ACADEMIC DEVELOPMENT SCHOLARSHIP PROGRAM AT \\ UNIVERSIDADE FEDERAL FLUMINENSE
}

André Luiz da Silva Coube ${ }^{1}$

\begin{abstract}
RESUMO: O presente artigo visa discutir a expansão recente no ensino superior público, com o foco nos estudantes vulneráveis socioeconomicamente e a permanência deste público nas Instituições Federais de Ensino Superior. No âmbito da assistência estudantil, a residência estudantil, o transporte, o restaurante universitário e o atendimento psicológico ganham destaque, porém há outras iniciativas institucionais importantes. Nesse contexto, é apresentado o programa Bolsa de Desenvolvimento Acadêmico, uma iniciativa que insere este público na pesquisa acadêmica com o objetivo de auxiliar na permanência nos cursos de graduação presencial da Universidade Federal Fluminense. A metodologia consistiu em revisar a literatura sobre a permanência estudantil relacionando com os objetivos do programa. Por fim, a restrição orçamentária limita a ampliação do programa, excluindo muitos estudantes que possuem direito.
\end{abstract}

Palavras-chaves: Bolsa de Desenvolvimento Acadêmico. Assistência estudantil. Acesso e permanência. Estudantes vulneráveis socioeconomicamente.

\begin{abstract}
This article aims to discuss the recent expansion in public higher education, with a focus on socioeconomically vulnerable students and the permanence of this public in the Federal Institutions Higher Education. In the field of student assistance, the student residence, transport, the university restaurant and psychological support are highlighted, but there are other important institutional initiatives. In this context, the Academic Development Scholarship program is presented, an initiative that inserts this public in academic research with the objective of supporting in the permanence in the undergraduate courses of the Universidade Federal Fluminense (UFF). The methodology consisted of reviewing the literature on student permanence relating to the objectives of the program. Finally, the budget constraint limits the expansion of the program, excluding many students who are entitled.
\end{abstract}

\footnotetext{
${ }^{1}$ Doutorando em Educação na Universidade Federal Fluminense (UFF). É mestre em Educação pela Universidade Federal do Estado do Rio de Janeiro (UNIRIO). Bacharel em História pela UNIRIO e licenciado pela AVM. É Técnico em Assuntos Educacionais na Pró-reitoria de Assuntos Estudantis na UFF. Email: andrecoube@id.uff.br
} 
Keywords: Academic Development Scholarship. Student assistance. Access and permanence. Socioeconomically vulnerable students.

\section{INTRODUÇÃO}

Nos últimos anos, houve uma expansão considerável no acesso ao ensino superior no Brasil. Políticas como o Programa Universidade para Todos - PROUNI, o Fundo de Financiamento ao Estudante do Ensino Superior - FIES (HERINGER, 2014; 2020), o Sistema de Seleção Unificada (SISU) via Exame Nacional de Ensino Médio (ENEM) e o Programa de Apoio a Planos de Reestruturação e Expansão das Universidades Federais (REUNI - Decreto $\mathrm{n}^{\mathrm{o}}$ 6069/07) ampliaram o ingresso ao nível superior. Junto a essas medidas, houve a criação da política de ações afirmativas, conhecida como a Lei de Cotas (Lei n $\left.{ }^{\circ} 12.711 / 12\right)$, que permitiu que metade das vagas nas Instituições Federais de Ensino Superior (IFES) fosse destinada exclusivamente para estudantes de ensino médio de escola pública. Dentro dessa reserva, há ainda a aplicação de filtros como renda, cor e pessoas com deficiência, tornando o acesso um pouco menos desigual.

Os novos ingressantes das IFES não chegam nas mesmas condições - nem nas Instituições de Ensino Superior (IES) privadas, porém o foco deste artigo é o ensino superior na rede federal. Muitos destes são os primeiros de suas famílias a ingressarem no ensino superior, com menor renda familiar, oriundos da escola pública, pretos e pardos e com trajetória escolar não linear (HONORATO; HERINGER; VARGAS, 2014), ou seja, depois que concluem o ensino médio passam pelo mercado de trabalho ou ficam sem ocupação antes do ingresso no ensino superior. Este novo perfil estudantil enfrenta enormes desafios para ter o acesso ao ensino superior e continua vivenciando grandes dificuldades na sua trajetória acadêmica quando consegue. Quanto à questão socioeconômica, cerca de 2,1 milhões de potenciais universitários são tão vulneráveis que não possuem condições de estudar mesmo sendo gratuito. Para que sejam incluídos no sistema educacional dependem de bolsas de pesquisa, restaurantes universitários, moradia e de outras ações institucionais para tornar viável a permanência com qualidade na universidade (VARGAS; PAULA, 2013).

Junto à expansão do acesso a esse público, foi necessário criar mecanismos que pudessem colaborar com a permanência desse novo perfil estudantil. Para isso, foi criado o Programa 
Nacional de Assistência Estudantil - PNAES, por meio do Decreto n ${ }^{\circ} 7234 / 10$, o qual aborda dez áreas que as IFES devem desenvolver suas ações para a ampliação das condições de permanência ${ }^{2}$.

Com o passar dos anos, vemos que as ações mais frequentes das IFES advindas do PNAES estão concentradas em residências estudantis, restaurantes universitários, transporte intercampi e oferta de consultas psicológicas. Nesse sentido, há uma grande associação das assistências estudantis com os profissionais de serviço social e de saúde. É compreensível essa associação mais direta, pois o público-alvo prioritário do PNAES são estudantes que apresentam renda bruta familiar per capita de até um salário mínimo e meio ou oriundos da rede pública de educação básica. Entretanto, há outras iniciativas institucionais que podem corroborar, visando a permanência com qualidade do seu público-alvo, para a adaptação ao novo nível de ensino.

O processo de formação no ensino superior é diferente do processo na educação básica e muitas IFES veem seus recém-ingressos como prontos para cursarem suas graduações. Entretanto, há um período de estranhamento (COULON, 2017) que acontece entre os estudantes nos seus primeiros períodos no novo nível de ensino. Iniciativas como, por exemplo, práticas esportivas, ações culturais e apoio pedagógico podem fazer com que o estudante se identifique e se engaje mais com o seu curso e com a sua instituição.

Nesse sentido, a inserção em uma pesquisa acadêmica possui o potencial de favorecer a afiliação universitária (COULON, 2017) e o aumento da motivação (TINTO, 2017). O presente artigo apresenta o programa Bolsa de Desenvolvimento Acadêmico (BDA) que é ofertado pela Pró-reitoria de Assuntos Estudantis (PROAES) na Universidade Federal Fluminense (UFF) como uma ferramenta que pode auxiliar os estudantes na permanência com qualidade na instituição a fim de diminuir os índices de retenção e evasão. A BDA tem como público-alvo exclusivo estudantes que apresentam renda per capita familiar igual ou inferior a um salário mínimo e meio, sendo considerados socioeconomicamente vulneráveis.

Tendo feito algumas considerações iniciais, trago, a seguir, um breve panorama das discussões sobre a permanência na graduação. Depois, mostro como o programa BDA pode se

\footnotetext{
${ }^{2}$ Estão descritas no $\int 1^{\circ}$ do Art. $3^{\circ}$ do PNAES que traz a seguinte redação: As ações de assistência estudantil do PNAES deverão ser desenvolvidas nas seguintes áreas: I - moradia estudantil; II - alimentação; III - transporte; IV - atenção à saúde; V - inclusão digital; VI - cultura; VII - esporte; VIII - creche; IX - apoio pedagógico; e $\mathrm{X}$ - acesso, participação e aprendizagem de estudantes com deficiência, transtornos globais do desenvolvimento e altas habilidades e superdotação.
} 
relacionar com pesquisas que abordam a permanência estudantil nas IES. Por fim, afirmo que o entendimento da educação pública como gasto impede que essa iniciativa atenda todos os estudantes vulneráveis socioeconomicamente interessados que possuem o direito ao acesso pleno à pesquisa acadêmica.

\section{A EXPANSÃO DO ACESSO E A DEMOCRATIZAÇÃO DA PERMANÊNCIA}

A Constituição Federal de 1988, em seu art. 205, discorre que a educação possui as seguintes funções: o pleno desenvolvimento da pessoa, o preparo para o exercício da cidadania e sua qualificação para o trabalho (BRASIL, 1988). Como as IES, especificamente públicos, podem cumprir bem o papel designado pela Carta Magna à educação em relação aos estudantes vulneráveis socioeconomicamente?

Uma pesquisa $^{3}$ da Associação Nacional dos Dirigentes das Instituições Federais de Ensino Superior (ANDIFES), divulgada em 2018, mostra que dois terços dos estudantes de graduação das IFES possuem renda de até um salário mínimo e meio per capita familiar. Os recursos orçamentários do PNAES estão sofrendo um decréscimo ao longo dos últimos anos assim como para a educação pública em geral e na UFF não é diferente ${ }^{4}$. A questão orçamentária para a assistência estudantil é uma preocupação crescente de gestores das IES públicas (HERINGER, 2014). É importante a manutenção e até a ampliação de bolsas de assistência estudantil, assim como alocação de pessoal e de recursos estruturais para um atendimento satisfatório das demandas que a expansão recente exige.

Entretanto, há uma ideia por parte de alguns organismos internacionais de que os países periféricos gastam muito com o ensino superior público. O Banco Mundial sugere, por exemplo, que o governo brasileiro diminuísse o custo por estudante universitário, reduzisse a gratuidade do ensino superior público e permitisse a ampliação do ensino superior privado (SANTOS, 2005). Esse pensamento também apareceu no atual governo federal. Inclusive houve uma fala do ex-ministro da educação, Abraham Weintraub, que afirmava que os professores das IFES eram zebras gordas ${ }^{5}$, fazendo uma referência aos seus salários e que só davam oito horas de

\footnotetext{
${ }^{3}$ Disponível em:: http://www.andifes.org.br/dois-tercos-dos-universitarios-das-federais-tem-renda-familiar-de15-salario-minimo/. Acesso em:: 14 set. 2020.

4 Disponível em:: http://www.uff.br/?q=noticias/11-02-2020/loa-determina-cortes-e-condicionamento-doorcamento-da-uff-para-2020 e em http://www.uff.br/?q=noticias/12-06-2019/o-que-o-bloqueio-orcamentariorepresenta-para-universidades-federais-desafios-e. Acesso em:: 19 set. 2020.

5 Disponível em:: https://oglobo.globo.com/sociedade/weintraub-afirma-que-vai-atras-da-zebra-gordaprofessores-que-ganham-de-15-mil-r-20-mil-23976141. Acesso em:: 14 set. 2020.
} 
aulas por semana. Weintraub desconsiderou as atividades administrativas, de pesquisa, de extensão, de orientação acadêmica, de participação em bancas, participações em congressos científicos, entre outras, além da alta qualificação acadêmica-profissional dos docentes.

Isso releva uma crise atual pela qual passa a universidade: a crise institucional. O Estado tem se transformado cada vez mais em comprador de bens e serviços produzidos pelo setor privado e menos em produtor. Nesse sentido, as restrições orçamentárias da universidade pública provocam que as mesmas procurem financiamentos privados, colocando em risco a sua autonomia e responsabilidade social (SANTOS, 1989). No século XX, os movimentos sociais avançaram na conquista da educação e da cultura como pilares da cidadania e a universidade se configurou como indissociável da democracia. Entretanto, nos últimos anos, a educação tem sido considerada como um serviço privatizável (CHAUí, 2003).

Essas propostas neoliberais buscam enfraquecer o ensino superior público. É importante que o orçamento destinado às universidades públicas não seja visto "pelo prisma do gasto público e sim como investimento social e político, o que só é possível se a educação for considerada um direito e não um privilégio, nem um serviço" (Ibid., p. 11). Nesse sentindo, a oferta de vagas em projetos de pesquisa para estudantes vulneráveis socioeconomicamente se configura como um investimento e um direito a uma política de assistência estudantil. A universidade pública deve ser vista como um bem de todos e um lugar onde se busca fazer justiça social através da justiça cognitiva (SANTOS, 2010) por valorizar os conhecimentos dos excluídos historicamente. Garantir a existência dos vulneráveis na universidade é compactuar com os objetivos do Brasil descritos nos incisos I e IV do art. $3^{\circ}$ da Constituição Federal de 1988 que dizem "I - construir uma sociedade livre, justa e solidária; IV - promover o bem de todos, sem preconceitos de origem, raça, sexo, cor, idade e quaisquer outras formas de discriminação.” (BRASIL, 1988). Sendo assim, a educação como um bem público e um direito social deve ter como princípios a equidade, a solidariedade e a inclusão. Como tal, ela forma cidadãos conscientes contribuindo para a democratização da sociedade, diplomam profissionais qualificados e ajuda para o desenvolvimento pleno do indivíduo. Cidadãos-profissionais com qualificações técnicas e responsáveis eticamente são os atores principais do fortalecimento econômico nacional. Porém, o fator econômico deve ser guiado pelo valor moral do bem comum (DIAS SOBRINHO, 2013).

Nesse sentido, os estudantes vulneráveis socioecomicamente possuem o direito de se qualificarem como bons profissionais, de se prepararem melhor para o exercício da cidadania e 
de se desenvolverem plenamente como pessoa no âmbito do ensino superior. Sendo assim, é importante pensar a assistência estudantil para esses estudantes nas IFES como um meio para a permanência com qualidade e posterior conclusão da graduação. A recente expansão do acesso ao ensino superior precisa ser estendida na democratização nas relações internas - longe de julgar como ideais as atuais formas de acesso - por meio de implementação de iniciativas que visem melhores condições de permanência dos estudantes vulneráveis e do entendimento da assistência estudantil como direito (HONORATO; HERINGER; VARGAS, 2014)

Embora, o acesso possua suas conquistas e contradições, há de se pensar na democratização das relações internas do ensino superior público. A política de ações afirmativas ao reservar vagas para as camadas historicamente excluídas provoca não somente o debate sobre a democratização do acesso, mas também sobre a democratização das relações internas, principalmente sobre a assistência aos estudantes vulneráveis socioeconomicamente. Apesar de ser positiva a implementação da política de ações afirmativas, há a grande preocupação com as dificuldades de permanência no ensino superior público dos estudantes beneficiados com essa política (HERINGER, 2014). Não é razoável pensar que a reserva legal de vagas para alguns perfis sociais garantirá as mesmas condições de permanência para todos. Os estudantes chegam ao ensino superior com percursos diversos, muito com trajetórias escolares não lineares (HONORATO; HERINGER; VARGAS, 2014). Por isso, é importante pensar como as IFES podem implementar políticas de assistência para os estudantes vulneráveis socioeconomicamente que, em grande parte, ingressam pelas cotas de renda.

A expansão do acesso não tem acontecido somente no Brasil, mas no mundo inteiro (NEVES; SAMPAIO; HERINGER, 2018). Do mesmo modo, as contradições entre acesso, permanência e democratização também são globais. Segundo Coulon (2017), a democratização do acesso ao ensino superior na França não foi acompanhada da democratização do acesso ao saber, principalmente no primeiro ano na graduação. $O$ autor alega que o ingresso na universidade representa a aprendizagem de novos códigos sociais formado por regras e saberes, sendo necessário que o estudante passe por três fases: estranheza, aprendizagem e afiliação. A primeira seria o primeiro momento de contato com o mundo acadêmico. Nesta fase, o estudante começa a sentir a diferença no ritmo das aulas, nas cobranças dos docentes e na mudança de regras. A segunda representaria as dúvidas, as incertezas e os questionamentos sobre o seu presente e o seu futuro, não reconhecendo mais a fase escolar anterior. A terceira significaria a fluência necessária dos códigos institucionais e intelectuais na universidade. 
A fase de afiliação está relacionada ao que Bourdieu (2010) chama de habitus. O habitus representa o capital cultural assimilado, que demanda tempo e investimento, neste caso, por parte do estudante universitário. Diferente do capital econômico que pode ser transmitido instantaneamente através de uma compra, venda, doação ou herança, o capital cultural é transmitido ao longo do tempo de forma dissimulada e inconsciente. Nesse sentido, alguns marcadores de afiliação e que poderiam ser considerados indícios da incorporação do babitus universitário seriam a "expressão escrita e oral, inteligência prática, seriedade, ortografia, presença de referências teóricas e bibliográficas nos trabalhos escritos, utilização espontânea do futuro anterior anunciador de uma perspectiva em construção” (COULON, 2017, p. 1247).

Na perspectiva de Tinto (2017), a motivação do estudante advém dos seus objetivos e é apoiada em três pilares: a autoeficácia, o senso de pertencimento e a percepção de currículo. A autoeficácia corresponde a crença que um estudante possui nele mesmo como capaz de superar algumas situações. O autor alerta que a baixa autoeficácia pode afetar todos os estudantes e não somente um tipo de perfil estudantil. O senso de pertencimento diz respeito à identificação e à adesão a um grupo específico dentro da universidade. Os estudantes que se sentem pertencentes a algum grupo e consequentemente a comunidade acadêmica não somente se engajam mais em seus cursos, mas também procuram engajar outros colegas. Os centros acadêmicos, as atléticas e os outros grupos estudantis são muitos importantes nesse sentido. Já a percepção de currículo está relacionada à percepção da relevância dos estudos. Este pilar contribui para que o currículo não seja visto como um mero acúmulo de informações, mas como um conjunto de valores.

Através desses estudos sobre a motivação e o engajamento do estudante com o seu curso de graduação e com a sua instituição, torna-se notório que a área da assistência estudantil não deve se limitar a concessões de recursos financeiros para os estudantes vulneráveis socioeconomicamente, embora estas sejam fundamentais para a melhoria das condições de permanência. Há várias iniciativas institucionais que podem contribuir para a permanência e a assistência ${ }^{6}$ como, por exemplo, práticas esportivas, ações culturais, apoio pedagógico ao estudante, entre outras. A seguir, trago uma iniciativa acontece na UFF, que é ofertada para todos os estudantes vulneráveis socioeconomicamente, no âmbito da assistência estudantil.

\footnotetext{
${ }^{6}$ Há de se fazer uma ressalva quanto ao uso dos termos assistência e permanência. As ações de permanência devem ser direcionadas para todos os estudantes universitários e ações de assistência devem ser destinadas para os estudantes em situação de vulnerabilidade, incluídas as dificuldades de ordem financeira. Entretanto, na prática, as ações de permanência e assistência estudantil estão integradas, superpostas ou mesmo confundidas (HONORATO; HERINGER; VARGAS, 2014).
} 


\section{BOLSA DE DESENVOLVIMENTO ACADÊMICO NA UFF: A PESQUISA COMO FERRAMENTA PARA A PERMANÊNCIA NO ENSINO SUPERIOR}

Antes de abordar o programa BDA em si, faz-se necessário situar, ainda que de forma breve, a universidade onde o mesmo se desenvolve, a UFF.

A origem da UFF se assemelha com a história de muitas outras IFES criadas no século XX: a partir da reunião de escolas superiores isoladas ${ }^{7}$. Em 2020, a universidade completou sessenta anos. Caracterizada pela forte interiorização, a UFF está presente em nove cidades do estado do Rio de Janeiro ${ }^{8}$, além da cidade de Oriximiná (PA).

Com a adesão da universidade ao REUNI, em 2007, (SILVA; BOROWSKY, 2018) a UFF dobrou a oferta de vagas entre 2006 e 2014, indo de 6.303 vagas para 14.028 vagas. Neste período, foram criados o Instituto de Ciências Exatas em Volta Redonda, o Instituto de Saúde de Nova Friburgo e a Escola de Engenharia em Petrópolis (esta criada em 2015). A expansão aconteceu ainda pela ampliação da infraestrutura das unidades já existentes. No mesmo período, o número total de cursos aumentou de 50 para 162. Já o número de matrículas foi de 25.344 para $52.936^{9}$.

Em 2010, logo após a promulgação do PNAES, a PROAES foi criada para atender a demanda do novo programa nacional, que pretendia ampliar as condições de permanência no ensino superior federal. A PROAES assumiu a gestão da antiga Bolsa Treinamento que existia desde 2006 (HONORATO; HERINGER; VARGAS, 2014), tendo seu nome modificado para o nome atual em 2012. Antes, a antiga Bolsa Treinamento ficava a cargo da Divisão de Assuntos Comunitários.

A PROAES lança dois editais da BDA geralmente em dezembro de cada ano (para a vigência entre março e dezembro do ano seguinte): um destinado para docentes e outro para estudantes. O primeiro é direcionado para aqueles que desejam submeter projetos de pesquisa para a avaliação da equipe de Divisão de Apoio Acadêmico (DAA) pelo Sistema de Bolsas (SisBol). Cada docente pode submeter até dois projetos e deve orientar no mínimo dois estudantes e no máximo cinco, indicando quais são os cursos desejados para cada vaga. Os

\footnotetext{
${ }^{7}$ Disponível em:: http://www.uff.br/?q=uff/hist\%C3\%B3ria. Acesso em:: 27 jan. 2021.

8 As cidades são Niterói (sede), Campos dos Goytacazes, Macaé, Rio das Ostras, Santo Antônio de Pádua, Volta Redonda, Petrópolis, Angra dos Reis e Nova Friburgo.

9 As informações referentes à ampliação de vagas, de cursos e de matrículas foram retiradas do Relatório de Gestão UFF 2006-2014. Disponível em:: http://www.noticias.uff.br/noticias/2014/11/relatorio-de-gestao-2006-2014. pdf. Acesso em:: 27 jan. 2021.
} 
professores responsáveis também podem convidar até dois professores para serem colaboradores. Sendo assim, cada projeto pode ter até três orientadores e até quinze estudantes.

Quanto ao edital para estudantes que desejam participar da BDA, os inscritos devem seguir as orientações contidas no documento e se submeterem a avaliação socioeconômica feita pela Coordenação de Apoio Social (CAS) da PROAES. O resultado é divulgado aproximadamente três meses depois do encerramento do prazo de inscrição. Logo após o resultado, os contemplados para participar do programa possuem a autonomia ${ }^{10}$ de se associarem nos projetos de pesquisa deferidos pela DAA, de acordo com a sua disponibilidade de horário e da oferta para o seu curso. O valor da bolsa mensal é de $\mathrm{R} \$ 440,00$ durante toda a vigência da BDA.

A vigência da bolsa é válida geralmente por nove meses abrangendo dois semestres letivos. Cada bolsista precisa cumprir algumas exigências descritas no edital como: estar inscrito, no mínimo, em quatro disciplinas nos semestres da vigência; não ser reprovado em mais de 50\% das disciplinas inscritas; possuir frequência igual ou superior a $75 \%$ em todas as disciplinas inscritas; enviar dois relatórios sobre as suas atividades executadas no projeto no meio e no final da vigência e participar da Semana de Desenvolvimento Acadêmico ${ }^{11}$. Por sua vez, os professores orientadores devem acompanhar seus bolsistas quanto ao processo de ensinoaprendizagem na graduação, principalmente quanto ao planejamento da grade de disciplinas, à frequência nas disciplinas inscritas e às avaliações. A orientação de pesquisa ocorre concomitantemente ao acompanhamento no ensino. Dessa forma, a BDA visa colaborar com a formação acadêmica integral ${ }^{12}$ aliada a ações de apoio socioeconômico.

Pinto (2015) apresenta algumas justificativas de candidatos para a solicitação da BDA, no ano de 2014, que corrobora com essa visão. Essas falas descrevem a importância que uma bolsa de pesquisa representaria tanto do ponto de vista socioeconômico quanto do acadêmico. Quatro dessas justificativas trazidas pela autora que exemplificam bem essa importância se encontram abaixo.

Solicito à Pró-Reitoria de Assuntos Estudantis, a concessão da bolsa

\footnotetext{
${ }^{10}$ Diferente de outros programas de pesquisa, os quais os professores são quem indicam os estudantes para os seus projetos, na BDA, os estudantes escolhem os projetos em que irão participar.

11 A Semana de Desenvolvimento Acadêmica é um evento que ocorre em duas fases. Na primeira, os bolsistas se apresentam nas suas unidades acadêmicas e há uma seleção para quem irá para a segunda fase. $\mathrm{Na}$ segunda, os bolsistas apresentam seus projetos para os outros bolsistas selecionados da mesma área de conhecimento e para uma banca. A segunda fase acontece no âmbito da Semana Nacional de Ciência e Tecnologia que ocorre anualmente no mês de outubro nas universidades federais.

${ }^{12}$ Vale ressaltar que é permitida a interdisciplinaridade por meio de cursos de áreas distintas dentro de um mesmo projeto. Um professor pode ofertar vagas para estudantes de economia, história e relações internacionais, por exemplo.
} 
Desenvolvimento Acadêmico 2014, a fim de garantir minha permanência na universidade e o desenvolvimento de um projeto técnico-científico, o que agrega (e muito) na minha vida acadêmica. Do ponto de vista social, é a minha única forma de renda. Visto que já estou concorrendo a Bolsa Acolhimento para alunos ingressantes 2/2013, e ela foi aprovada para mim. A minha situação de renda vem apenas da PROAES, única fonte de renda. Não posso mais trabalhar, visto que muita das vezes chego cedo à universidade, e só volto para casa para dormir, pois preciso estudar e dar conta das 10 disciplinas que eu tenho (11 professores no total, provas e atividades diversas). Necessito de total dedicação ao movimento estudantil, e a minha graduação/turma (pois sou o representante de classe do Curso de Farmácia). Meu tempo é inteiramente a UFF, não consigo ter nenhuma responsabilidade lá fora. Se eu tiver que trabalhar, terei que trancar muitas disciplinas e mesmo assim, não entraria em consenso com o ritmo do meu curso. Peço a concessão da bolsa por não ter nenhuma outra fonte de renda e para me dedicar mais ainda a minha prioridade, que é o estudo (Grifos da autora, Ernesto, 18 anos).

Solicito a bolsa, pois como estudante de uma universidade tenho o direito de um benefício para aperfeiçoar meus estudos. Uma vez que, recebendo a bolsa eu possa aprimorar cada vez mais meus conhecimentos. Pois, sem a bolsa, tenho dificuldades financeiras e dou aulas particulares para complementar (Betina, 21 anos).

Durante os dois anos que estive trabalhando como jovem aprendiz aprendi a ser "independente", por isso quando o contrato acabou me senti mal por ter, novamente, que depender da minha mãe para algumas coisas além do essencial, como comida e moradia. A bolsa de desenvolvimento acadêmico será, para mim, de grande relevância tendo em vista o fato de que o valor gasto com passagens, cópias de textos acadêmicos e lanches, por exemplo, absorvem todo o dinheiro que eu recebo de pensão, me privando até mesmo de adquirir, pelo menos, um dos livros indicados pelos professores e que são importantes para a minha formação. Além disso, sei que a oportunidade contribuirá e muito para a minha formação profissional e também para o aprimoramento dos conhecidos que eu já adquiri (Grifos da autora, Alice, 20 anos).

Não possuo renda e pretendo ter dedicação exclusiva à minha vida acadêmica para um melhor desempenho, e meus pais não têm condições de me sustentar, ainda mais agora que estão pagando o material da construção de um imóvel, e este material foi financiado (Grifos da autora, Pedro, 19 anos). (PINTO, 2015, p. 190191).

A participação na BDA é compreendida como muito relevante na trajetória acadêmica por parte dos estudantes que se candidatam através dessas justificativas, além da importância da bolsa para a diminuição da situação de vulnerabilidade socioeconômica.

As falas desses estudantes condizem com os estudos de Coulon (2017) que observou que os estudantes inseridos em pesquisa documental apresentavam mais êxito nas disciplinas do que aqueles que não participavam. A inserção em um projeto de pesquisa pode colaborar muito com a formação acadêmica através do engajamento do estudante com o seu curso e com a sua instituição. Ela pode favorecer o aprimoramento da leitura e da escrita acadêmica, a experiência prática em alguma área específica da formação e o maior aprofundamento de referências bibliográficas dentro de uma determinada área do conhecimento do curso. Todos esses potenciais benefícios da pesquisa colaboram com o ensino. 
No caso da BDA, percebe-se que há uma grande preocupação não somente com a produção da pesquisa em si, mas com o bolsista de forma integral. A frequência nas disciplinas, a não reprovação acima de 50\% e a inscrição em, no mínimo, quatro disciplinas demonstram que a pesquisa e o ensino devem caminhar juntos para a formação integral dos bolsistas. A atuação do orientador não se limita à orientação da pesquisa em si, mas se estende ao ensino de graduação. Os orientadores devem acompanhar também o desenvolvimento dos seus bolsistas no ensino. Ao mesmo tempo, além da formação acadêmica numa perspectiva integral, a bolsa mensal busca minimizar os impactos da situação de vulnerabilidade socioeconômica do bolsista.

Sendo assim, a BDA cumpre o seu objetivo que é tornar que o espaço da pesquisa na universidade seja apropriado pelo bolsista e com isso o mesmo se desenvolva academicamente também nas disciplinas do seu curso. Para que o estudante se dedique mais tempos aos estudos, a bolsa visa diminuir a necessidade de que o estudante busque uma renda para se manter na UFF. Com a maior dedicação aos estudos, a diminuição da retenção e da evasão é potencializada.

Por outro lado, a BDA proporciona que a pesquisa seja feita a partir de sujeitos historicamente excluídos, incluindo esse grupo na produção de conhecimento da universidade e dando-os visibilidade. A universidade pública democratiza suas relações internas e torna-se um lugar onde se busca fazer justiça social através da justiça cognitiva (SANTOS, 2010) por valorizar os conhecimentos dos excluídos historicamente. Dessa forma, a BDA representa um programa institucional a fim de dar assistência para uma melhor permanência dos bolsistas na universidade e esta pode enriquecer sua produção de conhecimento com os saberes desses sujeitos.

A BDA pode colaborar muito com os três pilares que sustentam a motivação do estudante de acordo com o Tinto (2017). A dedicação maior à leitura e à escrita, a experimentação prática em laboratórios, as idas a trabalhos de campo e a apresentação de trabalhos relacionadas ao projeto desenvolvido no âmbito da BDA podem contribuir para a autoeficácia na graduação. Ou seja, podem elevar a autoestima e a crença em si mesmo que as dificuldades acadêmicas podem ser superadas. Quanto ao senso de pertencimento, fazer parte de um grupo com o mesmo perfil socioeconômico e com os mesmos objetivos de pesquisa pode favorecer o engajamento com o seu curso e com a universidade através da identificação com os colegas e pelo apoio mútuo. E a percepção de currículo pode ser construída pela ampliação da visão sobre um campo de conhecimento dentro da área de formação, fazendo com que a graduação tenha mais sentido para o estudante. 
A pesquisa acadêmica também pode contribuir para a chegada à fase de afiliação (COULON, 2017) e pela incorporação do habitus universitário (BOURDIEU, 2010). O estudo em determinado campo de conhecimento contribui para a aprendizagem dos códigos institucionais e intelectuais da academia, já citados como os marcadores de afiliação e indícios da incorporação do habitus universitário.

Por outro lado, além do estudante aprender um novo conjunto de códigos e se engajar mais com a universidade, os grupos de pesquisa e os laboratórios da universidade podem se enriquecer com as vivências de estudantes vulneráveis socioeconomicamente e produzir novos olhares sobre ciência. Permite assim que a abertura ao outro seja o "sentido profundo da democratização da universidade, uma democratização que vai muito para além da democratização do acesso à universidade e da permanência nesta” (SANTOS, 1989, p. 52-53). Nesse sentido, a BDA pode se tornar uma via de mão dupla, a qual possibilita que o estudante vulnerável se aproprie de novos códigos acadêmicos e também permite que os grupos de pesquisa e os laboratórios conheçam outras subjetividades de modo a contribuir para a produção de conhecimento dos projetos. Um exemplo seria um projeto que pesquisasse a violência urbana em comunidades. A produção de conhecimento de um projeto como esse que envolvesse a participação de estudantes moradores de comunidade em situação de vulnerabilidade é muito diferente caso só tivesse estudantes não vulneráveis e que não morassem em comunidades. A produção de conhecimento se torna a partir de si e não sobre o outro. Dessa forma, a BDA pode contribuir para a democratização das relações internas na universidade.

Entretanto, a BDA possui a sua capacidade limitada de atender ao seu público-alvo devido à insuficiência de recursos orçamentários, deixando de atender muitos estudantes. A BDA oferece 1040 bolsas, porém há mais estudantes deferidos na avaliação socioeconômica do que número de vagas disponibilizadas no edital. Em 2019, 2276 estudantes foram deferidos. No ano anterior, foram 1470 estudantes deferidos e em 2017, houve 1584 pedidos deferidos ${ }^{13}$. Ou seja, apenas nos últimos três anos, 2210 estudantes que teriam direito à participação na BDA não conseguiram acessar ao programa devido a restrição de vagas. Mais de dois mil estudantes foram deferidos, mas não contemplados na BDA ${ }^{14}$.

\footnotetext{
${ }^{13}$ Dados obtidos junto ao SisBol.

${ }^{14}$ Como a lista de deferidos é maior do que o quantitativo de vagas, a CAS seleciona 1040 estudantes que possuem as rendas mais baixas dentre os que se inscrevem no edital. Sendo assim, os deferidos são todos aqueles que
} 


\section{CONSIDERAÇÕES FINAIS}

O artigo propôs discutir, de forma breve, os desafios advindos da expansão recente do acesso ao ensino superior público para a democratização da permanência de estudantes vulneráveis socioeconomicamente. A assistência estudantil não pode ser resumida à residência estudantil, ao transporte, ao restaurante universitário e à consulta psicológica, embora sejam fundamentais para a permanência. O PNAES traz um amplo leque de áreas que também devem ser promovidas como o esporte, a inclusão digital, a cultura e o apoio pedagógico.

Nesse sentido, achei pertinente apresentar um programa desenvolvido numa IFES, no caso, a UFF, que visa a inserção do estudante vulnerável na pesquisa acadêmica. Ao mesmo tempo que o programa concede a bolsa, o estudante é inserido na pesquisa acadêmica potencializando o desenvolvimento no ensino do mesmo através da apresentação de trabalhos, da experimentação prática, da leitura e da escrita. A inserção na pesquisa pode contribuir para a sustentação da motivação (TINTO, 2017) e para a chegada mais rápido da fase de afiliação (COULON, 2017) do estudante à universidade. É importante refletir como a assistência estudantil pode contribuir para a permanência efetiva de estudantes vulneráveis socioeconomicamente no ensino superior. Diversas iniciativas institucionais podem fazer com o que estudante veja mais sentido no seu processo formativo. Uma dessas iniciativas é a BDA que visa inserção na pesquisa acadêmica com potencial desenvolvimento no ensino e manutenção econômica do estudante.

Contudo, o programa sofre com as restrições orçamentárias assim como a assistência estudantil e a universidade de modo geral. Muitos estudantes deferidos não conseguem o acesso devido à limitação do número de bolsas ofertadas. As medidas neoliberais manifestadas em redução orçamentária e em congelamento de gastos públicos, promulgado pela Emenda Constitucional 95, não permitem um atendimento satisfatório e pleno aos estudantes vulneráveis socioeconomicamente e consequentemente para a sociedade. É necessário que a educação pública seja vista como um investimento e não gasto. O fim da educação não é acabar com as desigualdades sociais, porém não reconhecer que determinadas práticas e concepções podem aprofundá-las é negar as suas consequências socioeconômicas. Tratar as diferentes trajetórias pessoais de modo igual é abissalizar as desigualdades (SANTOS, 2010).

possuem renda bruta familiar per capita em até um salário e mínimo e meio e os contemplados são 1040 estudantes que possuem as menores rendas dentre os deferidos. 


\section{REFERÊNCIAS}

BOURDIEU, Pierre. Escritos de educação. NOGUEIRA, M.A; CATANI, A (orgs.). Petrópolis, RJ: Vozes, 2010.

BRASIL. Constituição (1988). Constituição da República Federativa do Brasil de 1988. Brasília, DF: Presidência da República.

Decreto $N^{\circ} 7.234$, de 19 de julho de 2010. Dispõe sobre o Programa Nacional de Assistência Estudantil - PNAES. Brasilia. 2010.

CHAUÍ, M. (2003). A universidade pública sob nova perspectiva. Revista Brasileira de Educação, (24). Disponível em:: http://www.scielo.br/scielo.php?pid=S1413-247820030003 00002\&script $=$ sci_abstract\&tlng=pt. Acesso em:: 27 ago. 2020.

COULON, Alain. O ofício de estudante: a entrada na vida universitária. Tradução de Ana Maria F. Teixeira. Educ e Pesqui., São Paulo, Vol. 43, n. 4, pp. 1239-1250, out/dez., 2017. Disponível em:: https://www.scielo.br/pdf/ep/v43n4/1517-9702-ep-43-4-1239.pdf. Acesso em:: 29 ago. 2020.

DIAS SOBRINHO, José. Educação Superior: bem público, equidade e democratização. Avaliação, Campinas; Sorocaba, SP, v. 18, n. 1, p. 107-126, mar. 2013. Disponível em:: http://www.scielo.br/pdf/aval/v18n1/07.pdf. Acesso em:: 14 set. 2020.

HERINGER, Rosana. Um balanço de 10 anos de políticas de ação afirmativa no Brasil. Tomo (UFS), v. 1, p. 17-35, 2014. Disponível em:: https://seer.ufs.br/index.php/tomo/article/ view/3184. Acesso em:: 27 set. 2020.

Políticas de ação afirmativa e os desafios da permanência no ensino superior. IN:

DIAS, C. E. S. B.; TOTI, Michelle C. da Silva; SAMPAIO, Helena; POLYDORO, S. A. J (Orgs.). Os serviços de apoio pedagógico aos discentes no ensino superior brasileiro. São Carlos: Pedro \& João Editores, 2020, p. 61-72.

HONORATO, Gabriela; VARGAS, Hustana Maria; HERINGER, Rosana. Assistência estudantil e permanência na universidade pública: refletindo sobre os casos da UFRJ e da UFF. Trabalho publicado nos Anais, n. 38o, 2014. Disponível em:: https://www.anpocs.com /index.php/papers-38-encontro/gt-1/gt25-1/9066-assistencia-estudantil-e-permanencia-nauniversidade-publica-refletindo-sobre-os-casos-da-ufrj-e-da-uff/file. Acesso em:: 27 set. 2020. 
NEVES, Clarissa Eckert Baeta; SAMPAIO, Helena; HERINGER, Rosana. A institucionalização da pesquisa sobre ensino superior no Brasil. Revista Brasileira de Sociologia, Vol. 06, No. 12, Jan-Abr/2018. Disponível em:: https://dialnet.unirioja.es /servlet/articulo?codigo $=6343218$. Acesso em:: 25 set. 2020.

PINTO, G. A política de assistência estudantil da UFF em duas faces: a institucionalidade dos processos e as perspectivas da demanda estudantil. 2015. 266f. Tese (Doutorado em Serviço Social) - Pontifícia Universidade Católica do Rio de Janeiro, Rio de Janeiro, 2015.

SANTOS, B. S. Da ideia de universidade à universidade de ideias. Revista Crítica de Ciências Sociais, n. 27/18, 1989, pp. 11-62.

A Universidade no Séc. XXI: Para uma Reforma Democrática e Emancipatória da Universidade. São Paulo: Cortez Editora ( ${ }^{\mathrm{a}}$ edição em 2005). Disponível em:: https://www.ces.uc.pt/bss/documentos/auniversidadedosecXXI.pdf Acesso em:: 18 set. 2020.

Para além do pensamento abissal: das linhas globais a uma ecologia de saberes. In: SANTOS, B. S.; MENESES, Maria P (orgs). Epistemologias do Sul. Edições Almedina S/A: Coimbra. 2010. Cáp. 1, p. 31-83.

SILVA, Renata M.; BOROWSKY, Micheli M. A implantação do reuni na UFF: ampliação de direitos ou precarização do ensino superior? Regae - Revista de Gestão e Avaliação Educacional. Santa Maria, v. 7, n.16, set./dez., 2018, p. 91-100. Disponível em:: https://periodicos.ufsm.br/regae/article/view/31483. Acesso em:: 31 jan. 2021.

TINTO, V. Through the Eyes of Students. Journal of College Student Retention: Research, Theory \& Practice, v. 19, n. 3, p. 254-269, dez. 2017. Disponível em:: https://journals. sagepub.com/doi/10.1177/1521025115621917. Acesso em:: 10 set. 2020.

VARGAS, Hustana Maria; PAULA, M. F. C. A inclusão do estudante-trabalhador e do trabalhador-estudante na educação superior: desafio público a ser enfrentado. Avaliação, Campinas; Sorocaba, SP, v. 18, n. 2, p. 459-485, jul. 2013. Disponível em:: http://periodicos.uniso.br/ojs/index.php/avaliacao/article/view/1590. Acesso em:: 11 set. 2020. 